Relations industrielles

Industrial Relations

\title{
La situation syndicale au Royaume-Uni. Rapport d'une mission du Bureau international du travail. Genève, 1961. 202, rue Queen, Ottawa, 141 pages. \$1.25.
}

\section{Gérard Dion}

Volume 17, numéro 1, janvier 1962

URI : https://id.erudit.org/iderudit/1021662ar

DOI : https://doi.org/10.7202/1021662ar

Aller au sommaire du numéro

\section{Éditeur(s)}

Département des relations industrielles de l’Université Laval

\section{ISSN}

0034-379X (imprimé)

1703-8138 (numérique)

Découvrir la revue

Citer ce compte rendu

Dion, G. (1962). Compte rendu de [La situation syndicale au Royaume-Uni. Rapport d'une mission du Bureau international du travail. Genève, 1961. 202, rue Queen, Ottawa, 141 pages. \$1.25.] Relations industrielles / Industrial Relations, 17(1), 90-91. https://doi.org/10.7202/1021662ar

Tous droits réservés @ Département des relations industrielles de l’Université Laval, 1962
Ce document est protégé par la loi sur le droit d'auteur. L’utilisation des services d'Érudit (y compris la reproduction) est assujettie à sa politique d'utilisation que vous pouvez consulter en ligne.

https://apropos.erudit.org/fr/usagers/politique-dutilisation/ 
And yet now we seem to be on the verge of witnessing even greater crimes against humanity, as without reason the Soviet leaders deliberately set out to poison humanity, and set the stage for the holocaust we have dreaded since the bombing of Hiroshima. While the people of the world are filled with dread and terror, Khrushchev tries to justify his actions by arguing that the Soviet Union is under threat of attack from his enemies. No one in the wide world believes anyone is threatening the Soviet Union with attack, not even Khrushchev.

In this country, and in all democratic countries, there has been a campaign of propaganda designed to acquaint people with the dangers of atomic war and the effects of radiation. Organizations like the Canadian Committee to Combat Radiation Hazards have made available to the people full information of the causes and effects of radiation. It is perfectly clear that no such democratic discussion has been permitted to take place in the Soviet Union, and the people in that nation are blissfully unaware of the destruction being sown across their own land and the rest of the world by the actions of their own leaders. It is impossible to image a war of the future and therefore impossible to imagine a future Nuremburg Trial, but if such a possibility exists there can be no doubt that among the prisoners at the bar will be Comrade Khrushchev.

This country, and all the countries of the world, must use the United Nations as the instrument and forum through which to let the Soviet Union understand that their actions in this instance are regarded across the world as a measure of the political ideals for which they stand. Not only do their leaders stand condemned before mankind, but the political system they espouse is on trial with them. International communism has no place in a democratic world of free peoples. Whatever other wars it may win, the Soviet Union has lost the war of ideas.

\section{RECENSIONS}

La situation syndicale au Royaume-Uni. Rapport d'une mission du Bureau international du travail. Genève, 1961. 202 , rue Queen, Ottawa, 141 pages. $\$ 1.25$.

Comme dans toutes les autres enquêtes entreprises par le B.I.T., la mission chargée d'étudier le cas de la GrandeBretagne, en 1960, s'est arrêtée à deux questions principales: savoir si les travailleurs sont libres de constituer des syndicats ou de s'y affilier et si les syndicats ont toute liberté d'exercer leurs fonctions.

Le rapport est d'autant plus intéressant et plus important que c'est dans ce pays qu'est né le mouvement syndical tel qu'on le connaît aujourd'hui à travers le monde. Celui-ci n'a donc pas pu prendre modèle sur aucun autre mouvement national. «Sa naissance n'a suivi aucun plan, et les syndicats n'ont pas été organisés en vue de s'inscrire dans un cadre préétabli ». Il n'est pas surprenant, non plus, qu'encore aujourd'hui il conserve les traces d'une certaine incohérence qui font son originalité et parfois aussi sa faiblesse. Aussi, les enqueteurs n'ont pas eu la besogne facile pour présenter une synthèse qui donne une image complète de la situation.

Ils ont divisé leur rapport en six chapitres: le mouvement syndical britannique (histoire, effectifs et organisation); la gestion des syndicats et la démocratie syndicale; participation des syndicats à la détermination des conditions de travail; participation des syndicats au règlement des différends du travail; par- 
ticipation des syndicats à la vie nationale (syndicats et collectivité, pouvoirs publics et syndicats, activités politiques des syndicats); la situation générale.

Si les syndicats britanniques manifestent une rare maturité et sont communément acceptés comme une des institutions sur lesquelles repose la démocratie britannique, ils ont encore quelques problèmes. Certains secteurs qui emploient surtout des travailleurs non manuels, comme les banques, la finance et les assurances continuent d'opposer une résistance à l'organisation syndicale. A l'intérieur du mouvement syndical, un traditionnalisme empêche d'effectuer des réformes de structure et de méthodes qui accroîtraient l'efficacité d'action. Les travaileurs hésitent à payer des cotisations syndicales suffisantes. L'organisation sur la base de la résidence des travailleurs plutôt que sur celle du lieu de travail donne un pouvoir aux délégués d'atelier qui ne va pas sans miner l'autorité des syndicats et occasionner trop de grèves non officielles.

On trouvera dans cet ouvrage les grandes lignes du régime des relations du travail en Grande-Bretagne ainsi que des détails intéressants sur l'action politique des syndicats et la façon que l'on s'y prend pour obtenir dans un établissement une syndicalisation à cent pour cent tout en recourant rarement à ce que l'on appelle chez nous des clauses de sécurité syndicale.

L'étude que nous présentent les enquêteurs du B.I.T. est forcément superficielle. Il existe d'autres ouvrages plus complets. Mais elle a le mérite de nous donner une vue d'ensemble préparée par une équipe compétente qui a observé des faits récents.

\section{Gérard Dion}

La situation syndicale en Suède. Rapport d'une mission du Bureau international du travail. Genève, 1961. 202, rue Queen, Ottawa. 125 pages. \$1.25.

Ce rapport se situe dans le cadre des autres qui ont été publiés sur la situation syndicale en U.R.S.S., aux EtatsUnis, et en Grande-Bretagne. Il est le résultat d'une enquête menée en Suède au cours de l'année 1960.

L'ouvrage est divisé en cinq chapitres: La Suède et le mouvement syndial; Les parties en présence; Les syndicats et les conditions d'emploi; Les différends et leur règlement; Les syndicats dans la vie de la nation.

La Suède occupe une place particulière dans les pays scandinaves. Le développement de son industrie, le degré du niveau de vie des citoyens, la généralisation de la sécurité sociale, le régime politique et économique en font un pays qui est parfois présenté comme un modèle dans le monde libre.

« L'une des caractéristiques les plus frappantes du marché de l'emploi en Suède est le degré d'organisation étonnant que les employeurs aussi bien que les travailleurs ont atteint. » L'effectif syndical s'élève à $80 \%$ du total des salariés et presque tous les employeurs appartiennent à la Confédération des employeurs suédois. On y rencontre aussi une centrale syndicale groupant les professionnels salariés, professeurs, avocats, médecins, etc.

L'organisation syndicale suédoise est remarquable par son unité, sa cohésion, sa discipline. Il n'existe pas de problème de reconnaissance syndicale puisque la Confédération des employeurs suédois a signé une entente à cet effet avec la Centrale ouvrière. Le gouvernement, lui aussi, admet le syndicalisme chez tous les fonctionnaires, y compris les membres des forces armées. Les syndicats sont définitivement acceptés dans toutes les sphères de l'activité économico-sociale. Les auteurs du rapport le soulignent: « La Suède peut être citée comme exemple d'un pays dans lequel le syndicalisme et la nécessité d'entretenir de bonnes relations professionnelles ont été admis une fois pour toutes. Pour en arriver à la position qu'ils occupent dans la vie de la nation, les syndicats ont davantage fait confiance à leurs propres efforts et au bien-fondé de leur programme qu'à la protection de la loi ».

La législation n'impose aucune limitation à l'action politique des syndicats ni même à l'utilisation des fonds syndicaux à des fins politiques. Bien que le parti qui possède le pouvoir en Suède soit supporté par les syndicats, et que le régime politique soit parfois qualifié de socialiste, il est assez curieux de noter qu'employeurs et travailleurs sont d'accord pour régler leurs problèmes en écartant le plus possible toute interven- 